\title{
Social distribution of cardiovascular disease risk factors: change among men in England 1984-1993
}

M Bartley, R Fitzpatrick, D Firth, M Marmot

\begin{abstract}
Objective-To investigate change in the social distribution of some of the main risk factors for cardiovascular disease in men in England during a period when inequality in cardiovascular disease mortality widened

Design-Age standardised comparison of the social distribution of seven known risk factors for cardiovascular disease (body mass index, waist to hip ratio, systolic and diastolic blood pressure, consumption of fresh green vegetables, leisure time exercise, cigarette smoking and levels of social support) in two large cross sectional representative samples of the English population.

Subjects-Men aged 20-64 years in the 1984 Health and Lifestyle Survey (excluding Scotland and Wales) first sweep and the 1993 Health Survey for England.

Main outcome measures-Mean values of continuous variables; age adjusted proportions of categorical variables; change in the relative index of inequality for each risk factor.
\end{abstract}

Results-The overall prevalence of cardiovascular disease risk factors improved during the period in which cardiovascular disease mortality was falling. The social distribution of cardiovascular disease risk factors, in contrast, did not become more extreme. Increases in the relative index of inequality for angina from 1.75 to 1.86 , for eating vegetables less than once a day from 1.76 in 1984 to 1.96 in 1993 , and an apparently larger increase in inequality of social support, from 1.92 to 2.53 were not statistically significant. In most cases the degree of inequality in risk factors tended to narrow nonsignificantly: for example the relative index of inequality fell from 5.02 in 1984 to 3.07 in 1993 for systolic blood pressure, from 5.60 to 4.29 for current smoking and from 6.24 to 4.19 for eating other than wholemeal bread as the main form of bread in the diet. The two statistically significant changes in inequality were in the direction of narrowing inequality: from a relative index of inequality of 2.12 to 0.90 for diastolic blood pressure $(p<0.01)$ and from 19.3 to $0.87(\mathrm{p}<0.01)$ for psychological distress as indicated by the General Health Questionnaire.

Conclusions-Healthier lifestyle options have not been adopted at a significantly faster rate by middle class than working class people over this time period. At the population level the change in risk factors is consistent with falling cardiovascular mortality. The change in the social distribution of risk factors within the population, however, shows little or no relation to the pattern of widening inequality in cardiovascular mortality. This may be because the effect is lagged, or because the adoption of healthier behaviour confers greater benefits on those in higher socioeconomic status groups.

(F Epidemiol Community Health 2000;54:806-814)

Effective interventions to reduce social variations in health are currently high on the policy agenda in Britain and internationally. ${ }^{1-3}$ As cardiovascular disease (CVD) mortality and morbidity contribute a sizeable proportion to overall health inequality, ${ }^{4}$ attempts to reduce these causes of death have obvious policy relevance.

Most attempts to intervene at the population level to prevent coronary heart disease have focused on changing the levels of risk factors such as smoking, lack of exercise and a diet low in fresh fruit and vegetables and high in saturated fat. Increased public understanding of risk factors, and acceptance of norms of "healthy behaviour" have been accompanied by sharp falls in mortality from CVD, without, however, affecting the social gradient: if anything this has widened. ${ }^{5-8}$ Questions have therefore been raised as to the effects of attempts to reduce the levels of CVD risk factors through health education, promotion and screening on social inequality in health. Some have argued that the prevention strategies used might even have the effect of widening these differentials, if those with greater education, income, and control over their daily lives were better able to adopt health promoting behaviours. $^{7910}$ Despite some contradictory evidence, ${ }^{11}$ it is widely assumed that more privileged social groups are more likely to adopt health promotion messages, with benefit to their risk factor profile.

This paper examines changes in the major risk factors for CVD in representative samples of the male population of England over the period 1984-1993. The paper uses relatively new measures of both social class and inequality. Social class is measured according to the Erikson-Goldthorpe schema. This classification was designed for use in international 
comparative studies of social mobility ${ }^{12}$ and has been used in recent international studies of health inequality. ${ }^{41314}$ Its theoretical base is in the relations and conditions of employment, the same as the new social classification recently adopted by the UK government for use in the 2001 Census and other official statistics. ${ }^{15}$ Class differences in risk factors are compared using the relative index of inequality (RII), a measure that makes use of the information on risk behaviour in every social class, rather than just comparing the extreme groups at the top and bottom. ${ }^{3}$

\section{Sample and measures}

SAMPLE

Cardiovascular screening data and interview data on lifestyle are available for a large representative sample of men and women in England in the Health and Lifestyle Survey $(1984-5)^{16}$ and the Health Survey for England 1993. ${ }^{17}$ The Health and Lifestyle Survey (HALS) is a clustered multi-stage sample of 9003 people in private households in England, Wales and Scotland. Questionnaires were personally administered, and followed up by a nurse visit during which physiological measurements were carried out. The Health Survey for England (HSE) is a continuous government survey that has been carried out since 1991 to monitor progress towards the government's Health of the Nation targets. The survey is designed to be representative of the adult population living in private households in England, taking account of the costs of fieldwork, and uses a geographically clustered stratified multi-stage sample. In the 1993 survey 13565 adults aged 16 and over were interviewed throughout the year; each sampled household was visited by an interviewer who administered the questionnaire and later by a nurse who carried out anthropometric and physiological measurements. Data in this paper consist of sub-samples of the HALS and the HSE: men resident in England, aged 20-64. The relation of risk factors to CVD in working age women is less well understood, and requires a more complex analysis involving consideration of social roles. ${ }^{18}$

\section{SOCIAL POSITION}

The Erikson-Goldthorpe class schema (E-G) distinguishes between those who are employers or employees, perform manual or non-manual work, and whose conditions of employment are regulated by a "service" rather than a "labour" form of contract. A service contract is characterised as one of trust, with higher levels of autonomy and job security, with the possibility of advancement through a clear career structure. A labour contract is one where supervision is tighter, and motivation to work is gained through the exchange of wages for set amounts of work. Levels of job security are lower, and there is no career structure. These characteristics of work are very similar to those distinguished by civil service grades in the Whitehall studies ${ }^{19}$ and position within E-G classification has previously been shown to be related to mortality ${ }^{20}$ and to cardiovascular risk factors $^{21}$ in the population of England and Wales. Occupations can be coded to the E-G schema as long as data are available on two items: the individual job title according to the Standard Occupational Classification (SOC) and full employment status. Full employment status requires questions on whether the person is self employed or an employee; whether they employ other persons and if so how many; whether they have managerial or supervisory responsibility; and the size of the firm where they work. Both of these items, SOC and full employment status, are asked in every census of England and Wales in a standard form, and similar questions were included in both the HALS and the HSE 1993. The algorithm for deriving E-G class from these items was made available by Nuffield College Oxford.

RISK FACTORS

These were divided into behavioural and physiological. Behavioural variables were smoking, leisure time exercise, consumption of fresh vegetables, fruit and wholemeal bread and diet. Physiological variables were body mass index (BMI), waist to hip ratio (WHR), systolic and diastolic blood pressure (SBP and $\mathrm{DBP}$ ). Inevitably, there were differences between the methods used in the two surveys.

\section{Physiological risk factors}

In the HALS: weight was measured in indoor clothing with shoes and coats or jackets removed: those who were pregnant or had missing limbs were not weighed. BMI was derived using assessed nude weight, calculated by subtracting a standard allowance for either light ( $0.9 \mathrm{~kg}$ for men, $0.6 \mathrm{~kg}$ for women) or heavy ( $1.5 \mathrm{~kg}$ for men, $0.9 \mathrm{~kg}$ for women) clothing. Height was measured in bare or stockinged feet in centimetres. Girth was measured at the waist in indoor clothing. The hip measurement, taken at the top of the iliac crest, was only available for two thirds of the sample as it was introduced after the beginning of the data collection. Blood pressure was measured using the Acutorr sphygmomanometer. Four serial recordings were made at one minute intervals: for consistency the mean of the last two are reported here. In the HSE informants were asked to remove shoes, jackets and heavy cardigans, heavy jewelry and heavy items from pockets before weight and height were measured. Pregnant women were not weighed and measured. Girth and hips were measured after the removal of all outer layers of clothing such as cardigans, jumpers and waistcoats, or any tight garments such as belts or corsets. Hip circumference was taken at the widest circumference over the buttocks and below the iliac crest. The Dinamapp 8100 monitor was used to measure blood pressure. Subjects were first seated for five minutes with their feet on the floor. Three measures were taken and the mean of the last two was used.

\section{Behavioural risk factors}

Differences between the two surveys were also found in respect of questioning about diet, 
smoking and exercise. These can be seen in detail from the table in the appendix, which describes the questions from which each measure was derived. Because the topic of this paper is change in social differentials rather than in overall prevalence of behaviours, the important biases to look for would be those that might create a false impression of either increasing or decreasing class specific prevalence. There was no obvious reason to think that members of the different social classes might have reacted differently to changes in the wording of the questions at the two time points.

\section{MORBIDITY MEASURES}

As well as change in risk factors, changes in the rates of self reported diabetes, treated high blood pressure, heart disease (angina, heart disease), longstanding illness and fair or poor self rated health and mental health as indicated by General Health Survey (GHQ) caseness were compared. Here again, there were differences in the ways in which measures were defined and questions asked. The wording of the questions on longstanding illness and self reported general health were slightly different. In the HSE, angina was diagnosed in two ways: the Rose angina questionnaire and a question on whether the respondent had ever suffered from angina. In the HALS, the Rose angina questionnaire was not administered, but respondents were asked whether they suffered from angina as part of the question on longstanding illness. To make the two measures comparable, the question on whether the respondent suffered from angina was used in both surveys, rather than the more objective measure. The prevalence of "treated high blood pressure" was judged in both surveys as the response to a questions on whether the respondent took any medication for high blood pressure. In the HALS this was derived from two questions: "At the moment, do you have anything on prescription?" and "Today, have you taken any prescribed pills for ... high blood pressure?" (the name of the medicine was recorded). In the HSE the equivalent question was "Are you currently taking any medicines, tablets or pills for high blood pressure?". The GHQ is a self administered questionnaire designed as a screening test to detect psychiatric disorders among those living in the community. It measures a person's current mental state by asking about symptoms that may have occurred over the past few weeks: answers therefore reflect disorders of a recent onset. Questions deal with general life satisfaction, social functioning, depression, anxiety and sleep disturbance. Each question has four possible answers. For negative questions such as "Have you lost much sleep over worry" a score of zero is given for "not at all" or "no more than usual", and one for "rather more than usual" or "much more than usual". For positive questions such as "have you felt on the whole you were doing things well" a score of zero is given to the answers "better than usual" or "about the same as usual" and a score of 1 to "less well than usual" or "much less well". The 30 item GHQ was administered in the HALS, and the 12 item GHQ in the HSE; a cut off point of six or more positive answers was used in HALS and four or more in HSE.

\section{STUDY DESIGN}

All tables show, for categorical variables, directly age standardised rates, taking the 1993 HSE as the standard population. The purpose of the standardisation was to ensure that changes over time were not attributable to different age distributions in the two samples. For continuous outcome variables such as blood pressure age has been standardised by analysis of covariance and adjusted means for each social class are shown. The estimates of the degree of inequality are carried out separately, using individual level data. Comparison of the degree of inequality in risk factors is carried out by calculating the RII, which is interpreted as an odds ratio, and $95 \%$ confidence intervals. The RII takes into account both the population size and the relative socioeconomic position of groups. It is calculated by regressing the rate of health problems or high risk behaviours of socioeconomic groups against the proportion of the population that has a higher position in the social hierarchy. A large RII implies that there are large differences between high and low social positions. ${ }^{3}$ For categorical variables, the RII is calculated by regressing the outcome variable against the fractional rank for each class, including age in the model. The resulting odds ratio may be interpreted as the amount of change in the likelihood of the outcome when the bottom is compared with the top of the fitted regression line. For continuous variables the slope index is simply the $\beta$ coefficient. The degree of inequality in each year is compared by means of a $t$ test for the difference between parameter estimates.

\section{Results}

Table 1 shows the distribution of working age men between E-G social classes in 1984 and 1993, and the mean ages in the classes. It demonstrates one of the advantages of this social classification in that the groups at the "top" and "bottom" are reasonably large, in contrast with the more traditionally used Registrar General's classification, and do not represent extremes of advantage or disadvantage.

Table 1 Numbers and (percentages) and mean age in each class. Men: age 20-64

\begin{tabular}{llllllll}
\hline & Year & $\begin{array}{l}\text { 1 Higher } \\
\text { professionals and } \\
\text { managers }\end{array}$ & $\begin{array}{l}\text { 2 Lower } \\
\text { professional and } \\
\text { managers }\end{array}$ & $\begin{array}{l}\text { 3 Routine } \\
\text { non-manual }\end{array}$ & $\begin{array}{l}\text { 4 Skilled } \\
\text { manual }\end{array}$ & $\begin{array}{l}\text { 5 Semiand } \\
\text { non-skilled } \\
\text { manual }\end{array}$ & Totals \\
\hline Number (\%) & 1984 & $376(17.2)$ & $374(17.1)$ & $181(8.3)$ & $637(29.2)$ & $613(28.1)$ & 2181 \\
Mean age & 1993 & $1019(21.5)$ & $914(19.3)$ & $349(7.4)$ & $1346(28.5)$ & $1096(23.2)$ & 4724 \\
& 1984 & 43.74 & 40.66 & 38.87 & 39.88 & 42.18 & 40.81 \\
\hline
\end{tabular}




\begin{tabular}{|c|c|c|c|c|c|c|c|c|c|}
\hline \multirow[b]{2}{*}{ Condition } & \multirow[b]{2}{*}{ Year } & \multirow[b]{2}{*}{ Number } & \multicolumn{5}{|c|}{ Erikson-Goldthorpe class } & \multirow[b]{2}{*}{$R I I(95 \% C I)$} & \multirow[b]{2}{*}{$\begin{array}{l}\text { RII } \\
\text { change* }\end{array}$} \\
\hline & & & $\begin{array}{l}1 \text { Higher } \\
\text { professional } \\
\text { and } \\
\text { managerial }\end{array}$ & $\begin{array}{l}2 \text { Lower } \\
\text { professional } \\
\text { and } \\
\text { managerial }\end{array}$ & $\begin{array}{l}3 \text { Routine } \\
\text { non-manual }\end{array}$ & $\begin{array}{l}\text { 4 Skilled } \\
\text { manual }\end{array}$ & $\begin{array}{l}5 \text { Semi and } \\
\text { non-skilled }\end{array}$ & & \\
\hline \multirow[t]{2}{*}{$\%$ With self reported angina or heart disease } & 1984 & 2181 & 2.2 & 1.8 & 4.9 & 2.3 & 3.2 & $1.75(0.74,4.14)$ & $t=0.1$ \\
\hline & 1993 & 4724 & 1.1 & 1.6 & 2.0 & 1.7 & 1.9 & $1.86(0.82,4.25)$ & $\mathrm{p}=0.92$ \\
\hline \multirow[t]{2}{*}{$\%$ On drug therapy for hypertension } & 1984 & 1882 & 3.8 & 4.9 & 3.7 & 3.3 & 4.2 & $1.12(0.50,2.44)$ & $t=0.70$ \\
\hline & 1993 & 4272 & 4.6 & 5.0 & 4.7 & 5.1 & 6.7 & $1.53(0.96,2.42)$ & $\mathrm{p}=0.48$ \\
\hline \multirow[t]{2}{*}{$\%$ With diabetes } & 1984 & 2181 & 2.1 & 2.0 & 1.3 & 1.8 & 1.0 & $0.62(0.19,1.96)$ & $t=0.1 .46$ \\
\hline & 1993 & 4724 & 2.7 & 1.1 & 1.7 & 2.0 & 3.2 & $1.66(0.84,3.25)$ & $\mathrm{p}=0.14$ \\
\hline \multirow[t]{2}{*}{$\%$ With fair to bad general health } & 1984 & 2177 & 17.5 & 21.0 & 24.4 & 30.1 & 36.9 & $4.54(3.18,6.44)$ & $t=1.51$ \\
\hline & 1993 & 4721 & 9.2 & 14.2 & 19.4 & 23.6 & 29.1 & $6.41(4.86,8.44)$ & $\mathrm{p}=0.13$ \\
\hline \multirow[t]{2}{*}{$\%$ With long term illness } & 1984 & 2181 & 26.2 & 28.9 & 29.8 & 27.7 & 30.5 & $1.29(0.93,1.81)$ & $t=0.85$ \\
\hline & 1993 & 4723 & 33.0 & 32.3 & 38.6 & 37.2 & 38.6 & $1.54(1.24,1.91)$ & $\mathrm{p}=0.40$ \\
\hline \multirow[t]{2}{*}{$\%$ GHQ cases $(\mathrm{GHQ} 30=6+)$} & 1984 & 1149 & 19.8 & 19.3 & 22.4 & 19.1 & 26.3 & $1.93(1.26,2.95)$ & $t=3.02$ \\
\hline & 1993 & 2712 & 14.8 & 14.6 & 13.6 & 12.3 & 14.7 & $0.87(0.65,1.17)$ & $\mathrm{p}=0.002$ \\
\hline
\end{tabular}

^Test for change in inequality between 1984 and 1993.

Between 1984 and 1993, in line with national trends, the size of the higher professional and managerial group had risen and that of the less skilled manual group had fallen: other groups remained similar in terms of their proportion of the population.

Table 2 shows the distribution of cardiovascular and related morbidity, general self rated health and long term illness in the five E-G social classes. These are expressed in terms of direct age standardised proportions. The RII is used to compare the degree of inequality between classes at the two time points.

Although there were apparent increases in some social gradients in cardiovascular related illnesses, for example, the RII for angina increased from 1.75 to 1.86 and that for receiving treatment for high blood pressure from 1.12 to 1.53 , the confidence intervals for the two time periods all overlap and the $t$ test confirms that the changes were not statistically significant. In line with other studies, this comparison of the HALS with the HSE has shown an increase in the prevalence of diabetes, which is largest among semi and unskilled manual workers and the appearance of a social gradient $(\mathrm{RII}=1.66)$ where none had been seen in 1984 $(\mathrm{RII}=0.62)$. This is most likely to be a result of better case finding, as is the increase in the proportion of men treated for high blood pressure, which is greatest in the routine and manual social classes. Intriguingly, rates of fair or poor self rated health decreased at the same time as reported long term illness prevalence rose in every social class. These findings are once again consistent with greater efforts at case finding, which would increase awareness and reporting of non-symptomatic chronic conditions such as high blood pressure. Like rates of less than good general health, the prevalence of GHQ caseness fell over the period. The RII showed a decrease in social inequality from 1.93 to 0.87 in the likelihood of being a GHQ case, and this change was statistically significant.

Table 3 shows the distribution of SBP and DBP, waist to hip ratio and BMI. Mean values are taken from analysis of variance with age as a covariate. In the case of these continuous variables, the degree of inequality has been assessed according to the $\beta$ (slope) in a linear regression model including age: a significant degree of social inequality is indicated if the confidence intervals do not include zero. The significance of the degree of change between 1984 and 1993 was assessed by the $t$ test for the difference between parameter estimates.

BMI has risen in all social groups. The relation between social class and BMI seems to have changed from a non-significant gradient of higher BMI in the lower social classes (RII=0.39), to a situation of more or less no class difference in $1993(\mathrm{RII}=0.03)$ : this change is not statistically significant. Because absolute differences in waist to hip ratio are very small, these are given to three decimal places. There was a significant tendency for waist to hip ratio to increase as social class fell in both 1984 (RII 0.013) and 1993 (RII 0.018) (the lower confidence limits exclude 0 ) but no significant change over time. DBP fell across all classes, and a significant gradient in diastolic blood pressure in 1984 ( $\mathrm{RII}=2.12$ ) disappeared in 1993 ( $\mathrm{RII}=-0.90)$ : this change in

Table 3 Change in physiological risk factors

\begin{tabular}{|c|c|c|c|c|c|c|c|c|c|}
\hline \multirow[b]{2}{*}{ Physiological risk factors } & \multirow[b]{2}{*}{ Year } & \multirow[b]{2}{*}{ Number } & \multicolumn{5}{|c|}{ Erikson-Goldthorpe class } & \multirow[b]{2}{*}{$R I I(95 \% C I)$} & \multirow[b]{2}{*}{$\begin{array}{l}\text { RII } \\
\text { change * }\end{array}$} \\
\hline & & & $\begin{array}{l}1 \text { Higher } \\
\text { professional and } \\
\text { managerial }\end{array}$ & $\begin{array}{l}2 \text { Lower } \\
\text { professional and } \\
\text { managerial }\end{array}$ & $\begin{array}{l}3 \text { Routine } \\
\text { non-manual }\end{array}$ & $\begin{array}{l}4 \text { Skilled } \\
\text { manual }\end{array}$ & $\begin{array}{l}5 \text { Semi and } \\
\text { non-skilled }\end{array}$ & & \\
\hline \multirow[t]{2}{*}{ Mean BMI } & 1984 & 1881 & 24.53 & 24.51 & 24.78 & 24.82 & 24.78 & $0.39 \quad(-0.17,0.95)$ & $t=1.21$ \\
\hline & 1993 & 4612 & 26.17 & 26.08 & 25.37 & 26.18 & 26.06 & $-0.03(-0.41,0.36)$ & $\mathrm{p}=0.23$ \\
\hline \multirow[t]{2}{*}{ Mean waist/hip ratio $(\mathrm{cm}) \dagger$} & 1984 & 1194 & 0.904 & 0.898 & 0.900 & 0.909 & 0.910 & $0.013(0.002,0.023)$ & $t=0.80$ \\
\hline & 1993 & 4172 & 0.894 & 0.900 & 0.896 & 0.907 & 0.907 & $0.018(0.011,0.024)$ & $\mathrm{p}=0.42$ \\
\hline \multirow[t]{2}{*}{ Mean DBP (mm Hg) } & 1984 & 1883 & 82.01 & 82.80 & 80.72 & 83.51 & 83.56 & $2.12(0.41,3.84)$ & $t=2.86$ \\
\hline & 1993 & 4108 & 77.97 & 78.50 & 77.55 & 77.38 & 77.61 & $-0.90 \quad(-2.1,0.27)$ & $\mathrm{p}=0.007$ \\
\hline \multirow[t]{2}{*}{ Mean SBP (mm Hg) } & 1984 & 1883 & 129.93 & 131.36 & 130.91 & 132.85 & 133.90 & $5.02(2.64,7.40)$ & $t=1.31$ \\
\hline & 1993 & 4141 & 135.83 & 136.53 & 137.99 & 137.75 & 138.16 & $3.07 \quad(1.42,4.72)$ & $\mathrm{p}=0.19$ \\
\hline
\end{tabular}

^Test for change in inequality between 1984 and 1993. †Because absolute differences in WHR are very small, results given to three decimal places. 
Table 4 Change in behavioural risk factors by social class, with comparison of RII

\begin{tabular}{|c|c|c|c|c|c|c|c|c|c|}
\hline \multirow[b]{2}{*}{ Behavioural risk factors } & \multirow[b]{2}{*}{ Year } & \multirow[b]{2}{*}{ Number } & \multicolumn{5}{|c|}{ Erikson-Goldthorpe class } & \multirow[b]{2}{*}{$R I I(95 \% C I)$} & \multirow[b]{2}{*}{$\begin{array}{l}\text { RII } \\
\text { change }\end{array}$} \\
\hline & & & $\begin{array}{l}1 \text { Higher } \\
\text { professional } \\
\text { and } \\
\text { managerial }\end{array}$ & $\begin{array}{l}2 \text { Lower } \\
\text { professional } \\
\text { and } \\
\text { managerial }\end{array}$ & $\begin{array}{l}3 \text { Routine } \\
\text { non-manual }\end{array}$ & $\begin{array}{l}4 \text { Skilled } \\
\text { manual }\end{array}$ & $\begin{array}{l}5 \text { Semi and } \\
\text { non-skilled }\end{array}$ & & \\
\hline \multirow[t]{2}{*}{$\%$ Current smokers } & 1984 & 2181 & 24.5 & 24.2 & 29.8 & 40.1 & 50.8 & $5.6(4.02,7.80)$ & $t=1.33$ \\
\hline & 1993 & 4715 & 19.7 & 25.0 & 27.7 & 37.9 & 42.0 & $4.29(3.41,5.40)$ & $\mathrm{p}=0.18$ \\
\hline \multirow{2}{*}{$\%$ Eating veg less than once per day } & 1984 & 2179 & 30.9 & 36.3 & 36.8 & 39.6 & 41.6 & $1.76(1.29,2.40)$ & $t=0.54$ \\
\hline & 1993 & 4702 & 32.4 & 34.6 & 38.0 & 41.1 & 42.9 & $1.96(1.58,2.42)$ & $\mathrm{p}=0.59$ \\
\hline \multirow[t]{2}{*}{$\%$ Drinking high fat milk } & 1984 & 2151 & 81.7 & 81.9 & 79.2 & 89.2 & 91.1 & $3.87(2.46,6.07)$ & $t=0.21$ \\
\hline & 1993 & 4496 & 27.7 & 32.7 & 34.6 & 44.7 & 51.1 & $3.66(2.94,4.57)$ & $\mathrm{p}=0.83$ \\
\hline \multirow[t]{2}{*}{$\%$ Whose main bread is not wholemeal } & 1984 & 2159 & 67.5 & 68.8 & 69.6 & 82.7 & 89.1 & $6.24(4.24,9.19)$ & $t=1.69$ \\
\hline & 1993 & 4321 & 65.1 & 70.8 & 69.1 & 82.5 & 83.4 & $4.19(3.24,5.42)$ & $\mathrm{p}=0.09$ \\
\hline \multirow[t]{2}{*}{$\%$ Eating fruit less than once per day } & 1984 & 2181 & 61.0 & 66.1 & 72.3 & 68.8 & 72.3 & $1.91(1.38,2.64)$ & $t=0.98$ \\
\hline & 1993 & 4716 & 56.2 & 56.3 & 60 & 60.9 & 64.2 & $1.57(1.27,1.94)$ & $\mathrm{p}=0.34$ \\
\hline \multirow[t]{2}{*}{$\%$ Not participating in any sport } & 1984 & 2176 & 37.2 & 46.8 & 45.3 & 54.1 & 60.0 & $3.36(2.43,4.64)$ & $t=0.07$ \\
\hline & 1993 & 4723 & 32.7 & 36.3 & 45 & 47.8 & 51.4 & $3.31(2.66,4.11)$ & $\mathrm{p}=0.94$ \\
\hline \multirow[t]{2}{*}{$\%$ With severe lack of social support } & 1984 & 2181 & 10.3 & 10.7 & 10.5 & 14.3 & 14.8 & $1.92(1.22,3.02)$ & $t=1.03$ \\
\hline & 1993 & 4642 & 13.0 & 14.8 & 15.1 & 16.6 & 23.1 & $2.53(1.92,3.35)$ & $\mathrm{p}=0.30$ \\
\hline
\end{tabular}

^Test for change in inequality between 1984 and 1993.

social gradient was statistically significant. By contrast, there was no significant difference between the RII for SBP in 1984 (RII=5.02) and 1993 (RII=3.07). No significance should be attributed to the changes in population levels of blood pressure, in view of the different ways in which the measures were taken. This does not, however, apply to the degree of social variation, which has clearly decreased (and reversed) in DBP.

Table 4 shows some of the changes in behavioural risk factors that have taken place between the two studies, in parallel with the changes in morbidity and physiological risk factors.

As indicated by the value of the RII, social gradients in most behavioural risk factors showed some degree of reduction. The proportion who reported themselves to be current smokers fell in all social classes except for lower professionals and managers: the decrease was largest in the highest and lowest of the E-G classes and the RII fell from 5.60 to 4.29 but this difference was not statistically significant. In most of the social classes, a very slightly higher proportion reported eating vegetables less than once a day in 1993 than 1984, although the questions asked in this case differed more than for many of the other risk factors (see appendix) and the RII showed a non-significant increase. Many fewer men were drinking mainly high fat milk in 1993 than in 1984, but the RII decreased from 3.87 to 3.66 . A similar increase in "healthy" behaviour accompanied by no change in social gradient was seen for participation in sport. The decrease in the social difference in eating wholemeal as the main bread (1984 RII $=6.24$; $1993 \mathrm{RII}=4.19)$ approached significance $(p=0.09)$. Fewer men were eating fruit less than once a day in 1993 (from 61 per cent to 56.2 in higher professionals and managers and from 72.3 per cent to 64.2 in semi and unskilled manual workers), and here again the gradient had not widened. Although there was a general increase in the prevalence of low social support, and this increase was larger in semi and unskilled workers (from 14.8 per cent to 23.1 per cent) than in higher professionals and managers (from 10.3 per cent to 13 per cent), this change was not statistically significant (RII $1984=1.92$; RII 1984=2.53).

\section{Discussion}

Studies have shown that people in less privileged social circumstances may be less able to understand, or more resistant to following, health education advice ${ }^{72}$ and there was some evidence that during the 1970s and early 1980s inequality in risk behaviours might be increasing. ${ }^{93} \mathrm{~A}$ consequence of this has been a widespread fear that policy initiatives such as the 1990 and 1993 GP contracts, which encouraged case finding and preventive activities in primary care ${ }^{52}$ could result in widening inequalities in risk factors and behaviours. The 1980s and 1990s are generally agreed to have been a period of sharply widening economic inequality. ${ }^{24}{ }^{25}$ It has been widely and plausibly assumed that economic inequality would have been accompanied by similar increases in other forms of social inequality, including those aspects of material and cultural circumstances that seem to influence health related behaviour. $^{2627}$

A comparison of social gradients in risk factors and behaviours found in the HALS and the HSE has been undertaken to examine the social gradients in health related behaviours and other cardiovascular risk factors recorded before and after these policy changes. This exercise is also useful in terms of beginning to monitor progress toward a healthier nation, by comparing the HALS with one of the early reports of the HSE. Many caveats must accompany an exercise such as this one. The surveys were not intended to be comparable although the HALS was to some extent used as a model for the HSE. The measures used have been chosen to be as comparable as possible, but there are inevitable differences (see appendix). The results show no significant increases in inequality in any of the risk factors. Where there were significant changes, in DBP and psychological well being as measured by the GHQ, these were in the direction of less rather than more social inequality.

The existence of social gradients in risk factors and behaviours in industrialised nations is well known ${ }^{28-31}$ and is now found in developing 
countries. ${ }^{32}$ Studies differ in the extent to which they present evidence that risk factors fully account for gradients in mortality. ${ }^{30}{ }^{33-35}$ There has been relatively little research examining trends over time in social differences in risk factors. The available evidence on widening social differences relates to a slightly earlier period than that covered here. ${ }^{23}$ Some data on trends in social differences in smoking, diet and exercise in the 1970 s were assembled by Whitehead $\left({ }^{36}\right.$ tables $11,13,14 ;{ }^{37}$ pages $\left.290-6\right)$, though trends in social gradients were not systematically analysed. The few papers that report on recent changes over time in social class differences in risk factors do not give strong support to the idea that social inequality in risk factors or behaviour is increasing. In the United States, there is evidence that increases in the social gradients in smoking, ${ }^{38}$ health knowledge, BMI, hypertension ${ }^{39} 40$ slowed or halted from the late 1980s. Similar findings have been reported in Australia. ${ }^{11}$

In the period 1984 to 1993 , this study shows encouraging indications that the efforts of health education may have resulted in rising rates of some healthier behavioural choices without further significant increases in social inequality. Consistent with findings of reports on trends in life expectancy for the population as a whole, many of the changes in morbidity and risk factors are positive. The general improvements in health found in national data are consistent with the observed increase in healthier behaviours such as consumption of fresh fruit, less high fat milk, and more sporting activity. A combination of falling rates of self reported less than good health with higher rates of longstanding illness may well be the result of better accessibility of screening and other preventive services, which have made people more aware of conditions that do not affect their subjective health status or functioning. This may also be one reason why there have been no increases in the social gradients for DBP or SBP. The increase in general levels of obesity runs against the trend towards better health in the population, and accords with the increase in diabetes.

The patterns reported here may be related to broader trends beyond England. Despite consistently declining rates of cardiovascular mortality, lower levels of socioeconomic advantage are associated with higher relative risk of cardiovascular disease for many Western countries. However, the existence and extent of socioeconomic differences in heart disease varies by European country. ${ }^{41}$ Both country specific evidence and structured overviews of evidence across nations have largely observed that increased relative risk of heart disease by socioeconomic status grew over the period 1960 to the early 1990s, regardless of study designs and populations studied. ${ }^{42}{ }^{43}$ The contribution of cardiovascular risk factors to explaining socioeconomic differences in mortality also varies considerably between European countries. ${ }^{44}$ There are several methodological problems in measuring socioeconomic status consistently and accurately for such analyses, so that it is not surprising that
KEY POINTS

- The late 1980 and early 1990s were a time of increasing social and economic inequality in the UK. It has been widely assumed that social inequalities in risk factors and behaviours widened along with cardiovascular mortality differentials.

- Using a validated measure of social class designed for international comparative studies, and a measure of inequality that uses information on the whole social gradient and not just the top and bottom groups, it seems that inequality in risk factors did not increase between 1984 and 1993 in men of working age in England.

- Inequality in the great majority of risk factors showed some narrowing, although few changes were statistically significant.

- The two statistically significant changes, in diastolic blood pressure and psychological wellbeing as measured by the GHQ, were in the direction of either narrowing or reversing social gradients.

- These changes may not be generalisable to other countries, as new policies introduced in the late $1980 \mathrm{~s}$ in the UK encouraged more preventive activity in primary care. But the measures used make it possible to carry out international comparative studies.

evidence is still inconsistent as to whether established risk factors are sufficient to explain social class differences in cardiovascular mortality even within a country. ${ }^{45}$ The availability of the E-G schema will assist the analysis and interpretation of international trends in inequalities in health, because efforts have been made to validate it and apply it across a range of European countries. ${ }^{13}$

During the period 1981 to 1991 , government vital statistics for England and Wales showed clear increases in social variation in heart disease mortality accompanying falling levels for the population as a whole. ${ }^{46}$ During this period decreases in mortality rates were much greater in men in professional and managerial occupations than in semi or unskilled manual occupations. In this light, the absence of widening social differences in risk factors may seem surprising, but the data presented here are consistent with a recent report from the United States ${ }^{40}$ between $1980-81$ and 1990-2, which found no widening of socioeconomic differences in risk factors. Recent data from the British General Household Surveys using a measure of socioeconomic position that is not designed for international studies, but that is more sensitive to extreme differences of socioeconomic status in a UK context (Dr M Jarvis, personal communication), also show a similar trend.

It is probable that the relation of risk factors to mortality involves a considerable lag time. Law and Wald have proposed a period of at least 25 years before changes in diet in France 
will result in French heart disease rates coming close to those in the UK. ${ }^{47}$ However, they also point out that while exposure to risk factors takes a long time to be reflected in increases in mortality, research on cholesterol and heart disease,${ }^{48}$ and smoking and lung disease, ${ }^{49}$ indicates that behavioural changes may be reflected in health improvements far more quickly (two to five years). The possibility that lagged effects of improvements in risk factors may eventually lead to reduced socioeconomic differences in cardiovascular mortality is supported by results from the Netherlands that have been interpreted as suggesting that the socioeconomic inequalities in CVD may have peaked in the mid 1980s with markedly declining gradients subsequently..$^{50}$

Although any link between the data from two specific samples presented here and population mortality data would have to be made with great caution, one study using linked risk factor and mortality data has shown consistent results. Vartiainen et al report one of the very few studies that are able to link risk behaviour directly to mortality and examine how far changes in the former are able to explain changes in the latter over time. They used the linkage capacity of the Finnish national statistics bureau to link risk factors to mortality in four cross sectional surveys over the period 1972 to $1987,,^{51}$ and observed that there were no social class differences in the changes in risk factor prevalence over time. During this period, mortality in blue collar workers fell in line with what would have been expected on the grounds of changes in risk factors, whereas mortality in white collar workers fell far more than would have been expected on the grounds of risk factor change alone. This kind of study is not possible in countries without the record linkage capacity of the Scandinavian national statistical organisations. The Health Surveys for England, Scotland and Wales may eventually be linked to mortality data if funding allows. In the absence of these kinds of data, it may be possible to combine data from regular monitoring of socioeconomic variation in risk factors with data on mortality at an appropriate time lag to gain a similar insight. ${ }^{47}$ If this were done, it would be most important that measures of risk factors and morbidity were designed to produce comparable results.

In conclusion, during a period of widening economic inequality in Great Britain, it might have been expected that previously reported increases in social inequalities in risk factors for CVD would have increased despite measures taken to increase preventive activity in primary care settings. ${ }^{52}$ Although cautious interpretation is needed, putting the results of these two surveys together indicates that this did not happen. If a continuation of widening social gradients was to be expected on the basis of economic trends over the period then this study gives support to the possibility that the efforts of health education and health promotion may now be acting more effectively as a defence against worsening health inequality. Other interpretations of the data are of course possible. Previous observations of widening social differentials may have been based on methodological differences from this study: both the measures of socioeconomic position and of inequality used here are relatively new in public health research. Although risk factors are important at the individual level they may be less so for explaining differences in CVD incidence between social groups. The trends presented here may not be generalisable to other countries that have not adopted similar approaches to prevention in primary care: more research would be needed to discover whether this is so. These trends do not represent progress towards the target of reducing health inequality, and bear witness to a worrying continuation of social differentials in health risk behaviours. However, they may indicate that it is inappropriate to take a defeatist or complacent attitude towards the potential contributions of primary care and public health.

We thank Professor Martin Jarvis of University College London for his comments on early drafts of this paper, and Dr Tarani Chandola of Nuffield College Oxford for his help and advice on the coding of the E-G classification.

Funding: this study was supported by UK Medical Research Council grant no G8802774.

Conflicts of interest: none.

1 Acheson D. Independent inquiry into inequalities in health: report. London: HMSO, 1998.

2 Mackenbach JP, Gunning-Schepers LJ. How should interMackenbach JP, Gunning-Schepers LJ. How should inter-
ventions to reduce inequalities in health be evaluated? $f$

3 Kunst AE, Mackenbach JP. Measuring socio-economic inequalities in health. Copenhagen: WHO, 1994.

4 Kunst A. Cross-national comparisons of socio-economic differences in mortality. Den Haag: CIP-Gegevens Koninklijke Bibliotheek, 1997.

5 Pappas G, Queen S, Hadden W, et al. The increasing disparity in mortality between socioeconomic groups in the united-states, 1960 and 1986. N Engl F Med 1993;329:103-

6 Quine S, Taylor R, Hayes L. Australian trends in mortality by socioeconomic-status using NSW small-area data, 1970-89. F Biosoc Sci 1995;27:409-19.

7 Winkleby MA. Accelerating cardiovascular risk factor change in ethnic minority and low socioeconomic groups. Ann Epidemiol 1997;7:S96-103.

8 Harding S, Bethune A, Maxwell R, et al. Mortality trends Harding S, Bethune A, Maxwell R, et al. Mortality trends
using the Longitudinal Study. In: Drever F, Whitehead M, using the Longitudinal Study. In: Drever F, Whitehead
eds. Health inequality. London: HMSO, 1998:143-55.

9 Davis SK, Winkleby MA, Farquhar JW. Increasing disparity in knowledge of cardiovascular-disease risk-factors and risk-reduction strategies by socioeconomic-status -implications for policy-makers. Am f Prev Med 1995;11: 318-23.

10 Bunton R, Nettleton S, Burrows R. The sociology of health promotion: critical analysis of consumption, lifestyle and risk. London: Routledge, 1995.

11 Bennett S. Cardiovascular risk-factors in Australia - trends in socioeconomic inequalities. $\mathcal{F}$ Epidemiol Community Health 1995;49:363-72.

12 Erikson R, Goldthorpe JH. The constant flux. Oxford: Clarendon, 1992.

13 Mackenbach JP, Kunst AE, Cavelaars AEJM, et al. Socioeconomic inequalities in morbidity and mortality in Socioeconomic inequalties in mor

14 Cavelaars AEJM, Kunst AE, Geurts JJM, et al. Morbidity differences by occupational class among men in seven European countries: an application of the EriksonGoldthorpe social class scheme. Int $\mathcal{F}$ Epidemiol 1998;27: 222-30.

5 Rose D, O'Reilly K. Constructing classes: towards a new social classification for the UK. Swindon: ESRC/Office for National Statistics, 1997

6 Cox BD, Blaxter M, Buckle ALJ, et al. The health and lifestyle survey: preliminary report. London: Health Promotion Research Trust, 1987.

17 Bennet N, Dodd T, Flatley J, et al. Health survey for England 1993. London: HMSO, 1995.

18 Bartley M, Sacker A, Firth D, et al. Social position, social roles and women's health in England: changing relationships 1984-1993. Soc Sci Med 1999;48:99-115.

19 Marmot MG, Davey Smith G, Stansfeld S, et al. Health inequalities among British civil-servants-the Whitehall II study. Lancet 1991;337:1387-93.

20 Bartley M, Carpenter L, Dunnell K, et al. Measuring inequalities in health - an analysis of mortality patterns using 2 social classifications. Sociology of Health and Ilness 1996;18:455-74. 


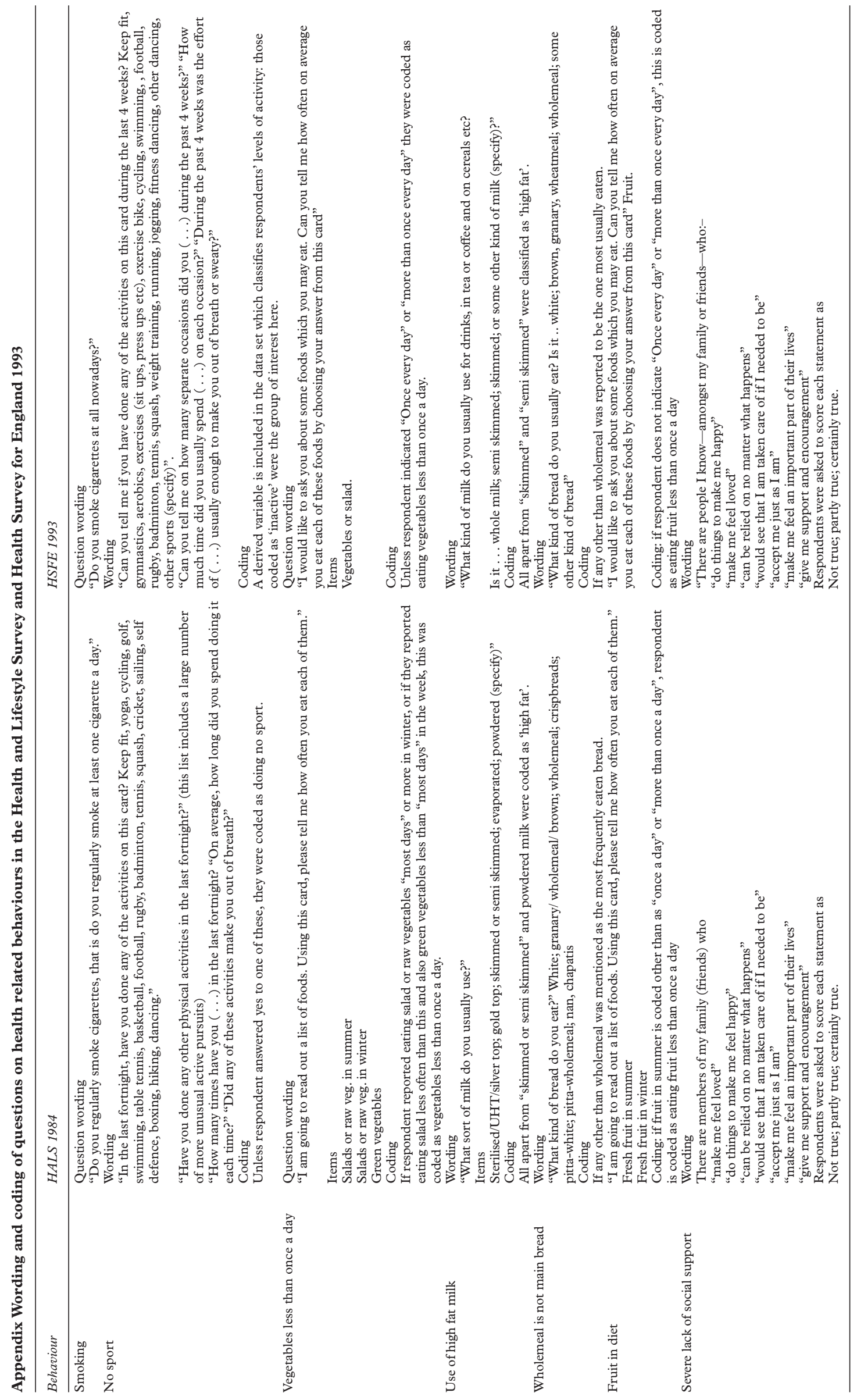


21 Bartley M, Sacker A, Firth D, et al. Understanding social variation in cardiovascular risk factors in women and men: the advantage of

22 Pocock SJ, Shaper AG, Cook DG, et al. Social class differences in ischaemic heart disease in British men. Lancet 1987;ii: 197-201.

23 Jarvis M. Patterns and predictors of smoking cessation in the general population. In: Bolliger C, Fagerstrom K, eds. Progress in respiratory research: the tobacco epidemic. Basel: $\mathrm{S}$ Karger, 1997:151-64.

24 Jenkins SP. Recent trends in the UK income distribution: what happened and why? Oxford Review of Economic Policy 1996;12:29-46.

25 Davey Smith G, Morris J. Increasing inequalities in the health of the nation. BMF 1994;309:1453-4.

26 Terris $M$. The development and prevention of cardiovascular disease risk factors: socioenvironmental influences. $\mathscr{f}$ 作

27 Stronks K, van de Mheen HD, Looman CWN, et al. Cultural, material, and psychosocial correlates of the socioeconomic gradient in smoking behavior among adults. Prev Med 1997;26:754-66.

28 Marmot M. Socioeconomic determinants of CHD mortality. Int F Epidemiol 1989;18:S196-202.

29 Luepker RV, Rosamond WD, Murphy R, et al. Socioeconomic status and coronary heart disease risk factor trends. The Minnesota Heart Survey. Circulation 1993;88:2172-9.

30 Lynch JW, Kaplan GA, Cohen RD, et al. Do cardiovascular risk-factors explain the relation between socioeconomicstatus, risk of all-cause mortality, cardiovascular mortality, and acute myocardial-infarction. Am 7 Epidemiol 1996;144 934-42.

31 Myllykangas M, Pekkanen J, Rasi V, et al. Hemostatic and other cardiovascular risk-factors, and socioeconomic-status among middle-aged Finnish men and women. Int $\mathcal{F}$ Epidemiol 1995;24:1110-16.

32 Nogueira A, Marcopito L, Lanas F, et al. Socioeconomic status and risk-factors for cardiovascular disease - a multistatus and risk-factors for cardiovascular disease - a multicenter collaborative study in the international clinical epidemiology

33 Marmot MG, Rose G, Shipley M, et al. Employment grade and coronary heart disease in British civil servants. $\mathcal{F}$ Epidemiol Community Health 1978;32:244-9.

34 Kaplan GA, Keil JE. Socioeconomic factors and cardiovascular disease: a review of the literature. Circulation 1992;88 1973-98.

35 Bucher HC, Ragland DR. Socioeconomic indicators and mortality from coronary heart-disease and cancer-a 1995;85:1231-6.

36 Whitehead M. The health divide. London: Health Education Council, 1986.
37 Townsend P, Davidson N, Whitehead M. The Black Report and the health divide. Harmondsworth,UK: Penguin, 1986. 38 Pierce JP, Fiore MC, Novotny TE, et al. Trends in cigarettesmoking in the United States-educational-differences are increasing. $\mathcal{F} A M A 1989 ; 261: 56-60$.

39 Winkleby MA, Fortmann SP, Barrett DC. Social-class disparities in risk-factors for disease-8-year prevalence patterns by level of education. Prev Med 1990;19:1-12.

40 Irbarren C, Luepker RV, McGovern PG, et al. Twelve-year trends in cardiovascular disease risk factors in the Minnesota Heart Survey. Are socioeconomic differences widening? Arch Intern Med 1997;157:873-81.

41 Kunst AE, Groenhof F, Andersen O, et al. Occupational class and ischaemic heart disease mortality in the United class and ischaemic heart disease mortality in the United 1999;89:47-53.

42 Hallqvist J, Lundberg M, Diderichsen F, et al. Socioeconomic differences in risk of myocardial infarction 19711994 in Sweden: time trends, relative risks and population attributable risks. Int f Epidemiol 1998;27:410-15.

43 Gonzalez MA, Rodriguez Artalo F, et al. Relationship between socioeconomic status and ischaemic heart disease in cohort and case-control studies: 1960-1993. Int f Epidemiol 1999;27:350-8.

44 Kunst AE, Groenhof F, Mackenbach JP, et al. Occupational class and cause specific mortality in middle aged men in 11 European countries: comparison of population based studies. EU Working Group on Socioeconomic Inequalities in Health. BM7 1998;316:1636-42.

45 Kunst AE, Groenhof F, Borgan JK, et al. Socio-economic inequalities in mortality. Methodological problems illustrated with three examples from Europe. Rev Epidemiol Sante Publique 1998;46:467-79.

46 Drever F, Whitehead M. Health inequalities. London: HMSO, 1997

47 Law M, Wald N. Why heart disease mortality is low in France: the time lag explanation. BMF 1999;318:1471-80.

48 Law MR, Wald NJ, Thompson SG. By how much and how quickly does reduction in serum cholesterol concentration lower risk of ischaemic heart disease? BMF 1994;308:36772 .

49 Doll R, Peto R. The causes of cancer: appendix E. $\mathcal{f}$ Natl Cancer Inst 1981;66:1291-305.

50 Otten FW, Bosma HH. The socio-economic distribution of heart diseases: changing gradients in The Netherlands. Soc Sci Med 1997;44:1349-56.

51 Vartiainen E, Pekkanen J, Koskinen S, et al. Do changes in cardiovascular risk factors explain the increasing economic difference in mortality from ischaemic heart disease in Finland? f Epidemiol Community Health 1998;52:416-19.

52 Department of Health and the Welsh Office. General practice in the National Health Service: a new contract. London: $\mathrm{DoH}$ and Welsh Office, 1989. 